\title{
Efficient Polymer Light-Emitting Diode Using Air-Stable Metal Oxides as Electrodes
}

\author{
By Henk J. Bolink,* Eugenio Coronado, Javier Orozco, and Michele Sessolo
}

In the last decades organic light-emitting diodes (OLEDs) have been extensively investigated as the potential next generation technology for flat-panel display and lighting. The interest in this technology has been triggered due to the reports of new breakthroughs in device efficiencies, lifetimes, and achievable colors, including white. ${ }^{[1]}$ However, these high performance levels are only obtained using multilayered devices. The multilayer architecture is obtained by sequentially evaporating the active species under high-vacuum conditions. Additionally, these devices use air-sensitive metals or charge-injection layers, which require rigorous encapsulation to prevent degradation. ${ }^{[2]} \mathrm{A}$ successful entry of OLEDs into the general lighting market requires, apart from high performance levels, a significant cost reduction of the devices. In this respect, it is of particular importance to be able to generate electroluminescence from devices using air-stable charge-injection interfaces. Some examples exist; however these devices rely on the presence of ionic charges to generate a dipole across the metal-light-emitting layer interface, and their reported lifetimes are low. ${ }^{[3-5]}$ Metal oxides hold, in principle, the promise of good charge injection, as they combine properties such as high transparency, good electrical conductivities, tuneable morphology, and the possibility of deposition on large areas with low-cost techniques. Recently, reports concerning the use of metal oxides as charge-injection layers for OLEDs were published. They range from ultrathin layers on the anode side to nanostructured layers on the cathode side of the devices. ${ }^{[6-8]}$ The use of a hole-blocking metal oxide material on the cathode side modifies the device efficiency by adjusting the charge balance in the device. ${ }^{[7]}$ A more beneficial use of the metal oxide layer is as an alternative for the cathode material. This is conceivable, as transition metal oxides, such as titanium oxide $\left(\mathrm{TiO}_{2}\right)$ and zinc oxide $(\mathrm{ZnO})$, have high electron mobilities and posses a low work function. ${ }^{[9]}$ The use of an unreactive metal oxide as the cathode is appealing, as this would allow the preparation of OLEDs with no or only simple encapsulation, reducing their cost significantly. Such a cost reduction greatly enables the use of OLEDs in display and especially lighting applications. It is also conceivable to prepare OLEDs consisting of both a metal oxide anode and cathode, in

[*] Dr. H. J. Bolink, Prof. Dr. E. Coronado, M. Sessolo Instituto de Ciencia Molecular, Universidad de Valencia P.O. Box 22085, 46071 Valencia (Spain) E-mail: henk.bolink@uv.es

Dr. J. Orozco

Departamento de Ingeniería Mecánica y Materiales Universidad Politécnica de Valencia Camí de Vera s/n, 46071, Valencia (Spain) which the organic charge-transport light-emissive layer is sandwiched between, and hence shielded from the environment. Recently, $\mathrm{TiO}_{2}$ and $\mathrm{ZnO}$ were employed as air-stable cathodes, as an alternative to low-work-function metals in polymer lightemitting diodes (PLEDs). ${ }^{[10-14]}$ These hybrid organic-inorganic light-emitting diodes (HyLEDs) have an inverted structure compared to OLEDs; the metal oxide cathode is used as the bottom contact, on top of or instead of the conductive substrate (normally, indium- or fluorine-doped tin oxide, ITO or FTO, respectively), and a gold anode is used as the top contact. HyLEDs take advantage of the peculiar characteristics of both organic and inorganic materials. A large variety of organic semiconductors is available, and it is possible to prepare tailor-made materials. Moreover, organic thin films can be easily processed through various printing techniques, and can be deposited on flexible substrates.

HyLEDs have shown promising performance, such as high luminance levels and low turn-on voltages, but they have not displayed high efficiency, primarily due to the high current density flowing through the device. ${ }^{[13]}$ Recently, we presented the operating mechanism of HyLEDs and showed why they only work with one specific type of light-emitting polymer (LEP), poly(9,9-dioctylfluorene-co-benzothiadiazole) (F8BT). ${ }^{[13]}$ This is due to the low energy of the lowest unoccupied molecular orbital (LUMO) of F8BT, such as to decrease as much as possible the energy gap between the metal oxide and the LUMO of the LEP. Apart from being a LEP with one of the lowest LUMO enegies, F8BT is also reported to have a high electron mobility. ${ }^{[15]}$ In spite of this, however, we showed that in a HyLED configuration the operational mechanism of the device is hole-dominated. The build-up of holes in the LEP is required, as it leads to the generation of a strong field over the LEP-metal oxide interface, which reduces the barrier for electron injection from the metal oxide into the F8BT. The main loss mechanism, however, is the imperfect blocking of holes at the LEP-metal oxide interface, resulting in a very high current density. This high current density is the main reason for the low device current efficiencies obtained. Additionally, the loss of holes from the interface reduces the interfacial field. Therefore, up to now, only high luminance values are obtained in the HyLED configuration when F8BT is used as the LEP. Employing more stable and more efficient LEPs, such as yellow-light-emitting polyphenylvinylenes and blue- and green-light-emitting poly(spiro)fluorenes, in the HyLED configuration did not lead to any significant electroluminescence. Therefore, to increase the device efficiency and be able to employ more efficient and stable LEPs then F8BT, it is paramount to reduce the loss of holes at the LEP-metal oxide interface. This can potentially be achieved by placing a low molecular weight hole-blocking molecule, such as 
1,3,5-tris(2- $N$-phenylbenzimidazolyl) benzene, between the metal oxide and the LEP. However, in that case it is no longer possible to use solution processable LEPs, as this deposition would dissolve the hole-blocking layer. One of the main appealing features of the HyLED configuration is its simplicity and potential to prepare with solution-based processes. Therefore, another approach to a hole-blocking material must be investigated. Various reports exists on thin inorganic insulating layers in OLEDs, which block holes and increase the electron injection; however, the obtained efficiencies were low. ${ }^{[16]}$ Another example used in OLEDs is a thin layer of cesium carbonate $\left(\mathrm{Cs}_{2} \mathrm{CO}_{3}\right)$ deposited between the electron-injecting contact and the LEP, which results in a significant increase in efficiency attributed to an increase in electron injection combined with efficient Blocking of holes, ${ }^{[17-20]}$ adopted to the Hy LED configuration by morii et at. ${ }^{[21]}$

In this work we describe the effect of the deposition of a thin layer of $\mathrm{Cs}_{2} \mathrm{CO}_{3}$ between the metal oxide cathode and the well-known LEP poly(phenylenevinylene) (PPV) co-polymer, "super yellow" (SY, Fig. 1), supplied by Merck. SY yields efficient OLEDs with operational lifetimes up to 100000 hours, and is thus a representative example of stable and efficient LEPs. ${ }^{[22]}$ Very bright HyLEDs, with a luminance above $20000 \mathrm{~cd} \mathrm{~m}^{-2}$ at $10 \mathrm{~V}$ and a maximum current efficacy of $8 \mathrm{~cd} \mathrm{~A}^{-1}$, were obtained, showing the effectiveness of $\mathrm{Cs}_{2} \mathrm{CO}_{3}$ as a hole-blocking/ electron-injecting layer. This performance is a large improvement compared to previous reports, and shows that the HyLED configuration can be used in more efficient and stable LEPs. These results demonstrate that HyLEDs are real competitors to conventional OLEDs. Additionally, it confirms the proposed operational mechanism of HyLEDs as being hole-dominated devices. ${ }^{[13]}$ The effect of the layer thickness of the $\mathrm{Cs}_{2} \mathrm{CO}_{3}$ on the device performance was evaluated, suggesting that the holeblocking effect of this layer was due to a partial doping of the LEP caused by a chemical reaction with the $\mathrm{Cs}_{2} \mathrm{CO}_{3}$.

The HyLED device layout is presented in Figure 2. The devices were prepared as follows. Thin $\mathrm{ZnO}$ films were deposited by spray pyrolysis onto prepatterned ITO glass plates, following a procedure similar to previous reports. ${ }^{[23,24]} \mathrm{Cs}_{2} \mathrm{CO}_{3}$ can be deposited from solution, and is thus compatible with low-cost electroluminescent devices. However, to obtain maximum control over the layer thickness, in this study the layer was

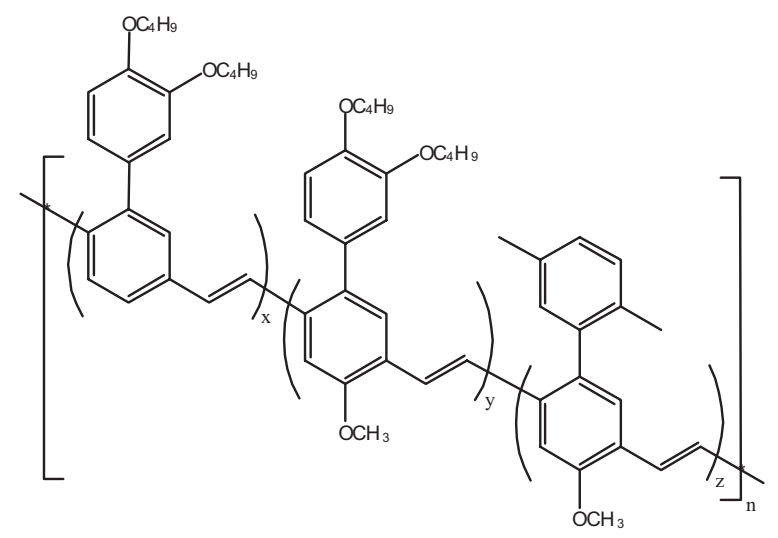

Figure 1. Chemical structure of the light-emitting poly(phenylvinylene), super yellow (SY).

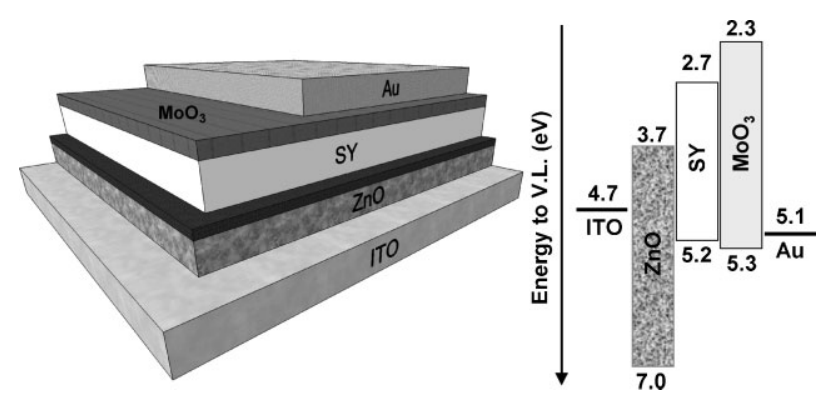

Figure 2. Scheme of the HyLED architecture (left) and energy levels of the materials involved in the HyLED (right).

thermally evaporated on top of the metal oxide. After deposition, the substrates were annealed outside the glove box in ambient conditions at $120{ }^{\circ} \mathrm{C}$ for 10 minutes. $\mathrm{Cs}_{2} \mathrm{CO}_{3}$ changes its constitution after thermal evaporation and subsequent exposure to air at elevated temperatures and to unknown compounds. ${ }^{[25]}$ Nevertheless, in this paper we will refer to this layer as " $\mathrm{Cs}_{2} \mathrm{CO}_{3}$ " to enhance the readability. The exposure to air at elevated temperatures was conducted to ensure a complete conversion of the Cs-compounds formed during the vacuum deposition process to compounds stable in air. Subsequently, SY $80 \mathrm{~nm}$ thick was spincoated on top of this annealed $\mathrm{Cs}_{2} \mathrm{CO}_{3}$-covered metal oxide substrate, and transferred to a high-vacuum chamber integrated in an inert-atmosphere glovebox, to thermally evaporate the $\mathrm{MoO}_{3}$ hole-injection layer and the gold anode. Although the work function of gold is close to the HOMO energy of SY, no efficient hole injection was observed without the presence of a thin $(5-20 \mathrm{~nm}) \mathrm{MoO}_{3}$ layer. The reason for the high hole-injection barrier for the bare SY-Au contact is not understood. The presence of the hole-injecting metal oxide layer is beneficial not only for the injection of holes but also as an additional barrier for moisture, as now the LEP is sandwiched between two metal oxide contacts.

A HyLED containing SY as the LEP but without an extra hole-blocking layer between the LEP and the $\mathrm{ZnO}$ was prepared using $\mathrm{ZnO}$-coated ITO as the transparent cathode and $\mathrm{MoO}_{3}$ and $\mathrm{Au}$ as the anode (Fig. 2). The current density - voltage $(J-V)$ characteristic of this reference device is depicted in Figure 3. The turn-on voltage for the current flow of these devices is as low as $0.2 \mathrm{~V}$, which is extremely low for a yellow-light-emitting polymer (band gap $\sim 2.1 \mathrm{eV}$ ). The turn-on voltage for a predominantly hole-only device is, in a first approximation, determined by the build in potential resulting from the difference in work function of the anode and cathode. In this case, according to Figure 1, that difference is approximately $1.6 \mathrm{eV}$, deduced from the difference between the conduction band of $\mathrm{ZnO}$ and the valence band of $\mathrm{MoO}_{3}$. However, if the metallic contacts are used to determine the built-in voltage, this results in a value of $0.4 \mathrm{eV}$, a value closer to the experimentally observed. As HyLEDs are hole-dominated devices, the low turn-on voltage is indicative of a very low injection barrier for holes at the $\mathrm{MoO}_{3}$-SY interface. ${ }^{[13]}$ This is consistent with reports on $\mathrm{MoO}_{3}$ as highly doped semiconductors. ${ }^{[26]}$ The current density reaches high values of $>1000 \mathrm{~A} \mathrm{~m}^{-2}$ in agreement with the good hole-transporting properties of SY. However, barely any electroluminescence was observed for this device, in agreement with earlier results. This implies that there 


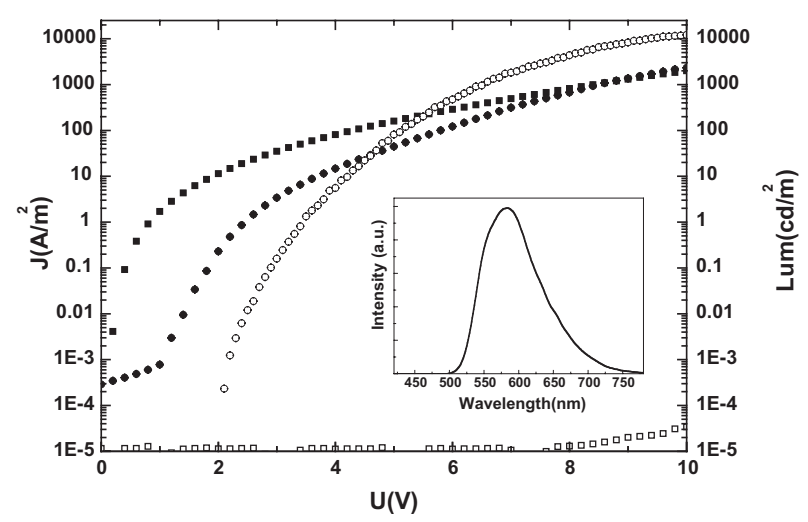

Figure 3. Current density (full symbols) and luminance (open symbols) versus applied voltage for an ITO/ZnO/SY $/ \mathrm{MoO}_{3} / \mathrm{Au}$ (squares) and an $\mathrm{ITO} / \mathrm{ZnO} / \mathrm{Cs}_{2} \mathrm{CO}_{3}(5 \mathrm{~nm}) / \mathrm{SY} / \mathrm{MoO}_{3} / \mathrm{Au}$ (circles) devices, where ITO-ZnO was biased negatively. The inset shows the electroluminescence spectra recorded at $5 \mathrm{~V}$ for the $\mathrm{ITO} / \mathrm{ZnO} / \mathrm{Cs}_{2} \mathrm{CO}_{3}(5 \mathrm{~nm}) / \mathrm{SY} / \mathrm{MoO}_{3} / \mathrm{Au}$ device.

is virtually no electron injection up to driving voltages of $8 \mathrm{~V}$, due to the large barrier between the conduction band of the $\mathrm{ZnO}$ and the LUMO of the SY. The large hole currents do not result in a strong interfacial field over the ZnO-SY interface, which, similarly in our earlier report we attribute to insignificant hole blocking at that interface.

In Figure 3, the $J-V$-luminescence $(L)$ characteristics of a SY-based HyLED, in which a thin layer of $\mathrm{Cs}_{2} \mathrm{CO}_{3}$ was placed between the LEP and the $\mathrm{ZnO}$ layer, is depicted.

The presence of the thin $\mathrm{Cs}_{2} \mathrm{CO}_{3}$ layer results in a large change in the current density and luminance curves. First, the current density rises after a turn-on voltage of approximately $1 \mathrm{~V}$, which is increased with respect to the device without the $\mathrm{Cs}_{2} \mathrm{CO}_{3}$ layer by $0.8 \mathrm{~V}$. The origin of this increase is not clear at this time, but can be associated to i) additional resistance due to the insulating $\mathrm{Cs}_{2} \mathrm{CO}_{3}$ layer or ii) the appearance of a notable build-in voltage determined by the work-function difference of the two electrodes. The final level of the current density, however, reaches values similar to that of the device without the $\mathrm{Cs}_{2} \mathrm{CO}_{3}$ layer. More striking is the change in luminance, which turns on at around $2 \mathrm{~V}$ and reaches levels of $12000 \mathrm{~cd} \mathrm{~m}^{-2}$ at $10 \mathrm{~V}$. This is an enormous improvement compared to the device without the $\mathrm{Cs}_{2} \mathrm{CO}_{3}$ layer. We interpret the delay in turn-on of the luminance with respect to that of the current density as an indication that the emission zone is initially very close to the $\mathrm{ZnO}$ interface, which effectively quenches the excitons. Upon increasing voltages and current densities, the emission zone shifts towards the center of the SY layer, and light emission starts. This is in agreement with the small current densities observed, due to the electron-hole recombination close to the $\mathrm{ZnO}$ interface. This indicates that the $\mathrm{Cs}_{2} \mathrm{CO}_{3}$ layer works as an effective electron-injection and hole-blocking layer. In this device, a maximum current efficacy of $6.5 \mathrm{~cd} \mathrm{~A}^{-1}$ is reached, which is close to what is observed for a SY-based OLED, demonstrating the potential of the HyLED configuration. The electroluminescence spectrum is typical of the SY polymer, and is not affected by the HyLED configuration.

In order to further investigate the functionality of the $\mathrm{Cs}_{2} \mathrm{CO}_{3}$ layer, a series of HyLEDs with different $\mathrm{Cs}_{2} \mathrm{CO}_{3}$ layer thicknesses were prepared. Figure 4 shows the $J-V-L$ graphs observed for layer thicknesses of the evaporated $\mathrm{Cs}_{2} \mathrm{CO}_{3}$, ranging from 0.25 to $5 \mathrm{~nm}$ as indicated by the quartz crystal sensor used for the thermal evaporation. Note that the atomic radius of $\mathrm{Cs}$ is in the order of $0.26 \mathrm{~nm}$, which means that the thinnest layers cannot result in full film coverage.

Nevertheless, with a thickness of only $0.25 \mathrm{~nm}$ of $\mathrm{Cs}_{2} \mathrm{CO}_{3}$, a shift in the onset of the current flow is already observed. Simultaneously, even for this thin $\mathrm{Cs}_{2} \mathrm{CO}_{3}$ layer, the luminance also increases dramatically compared to the reference HyLED without any $\mathrm{Cs}_{2} \mathrm{CO}_{3}$. At a bias of approximately $7 \mathrm{~V}$, the current densities of all devices are more or less identical. The highest current density is observed for a device with a $\mathrm{Cs}_{2} \mathrm{CO}_{3}$ layer thickness of $2 \mathrm{~nm}$. This device also reaches the highest luminance of $20000 \mathrm{~cd} \mathrm{~m}^{-2}$ at a driving voltage of 10 volts, which is very close to what is observed from a standard OLED device at these voltages. The current efficiency (inset of Fig. 4a) increases significantly from the reference device to the device with a $\mathrm{Cs}_{2} \mathrm{CO}_{3}$ layer thickness of $0.25 \mathrm{~nm}$, after which it increases steadily until it reaches a maximum of $8 \mathrm{~cd} \mathrm{~A}^{-1}$ for a device with a

a)

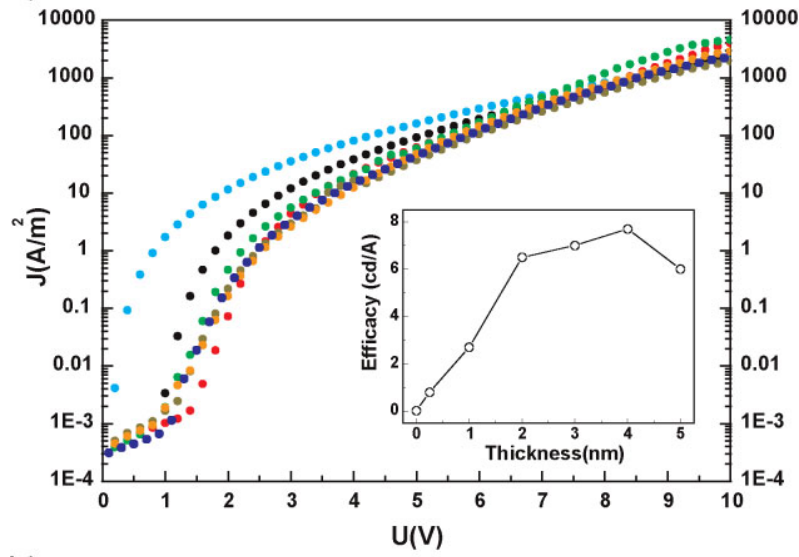

b)

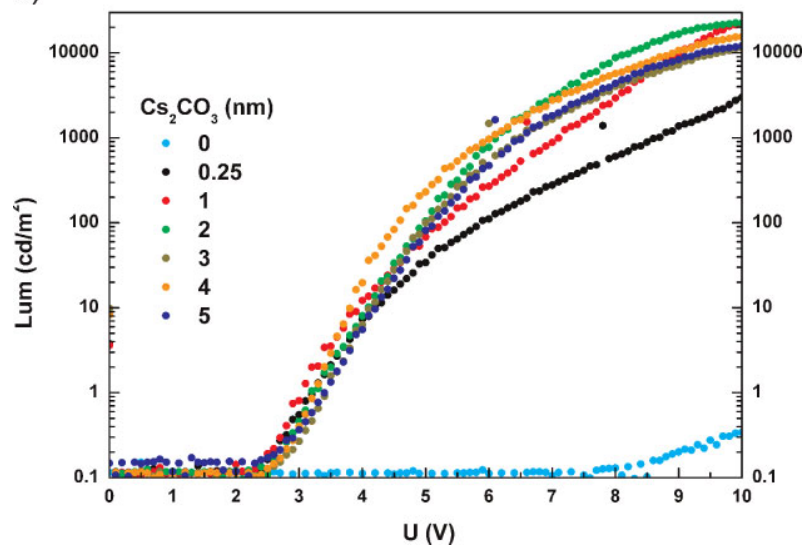

Figure 4. a) Current density and b) luminance versus applied bias for an ITO $/ \mathrm{ZnO} / \mathrm{Cs}_{2} \mathrm{CO}_{3} / \mathrm{SY} / \mathrm{MoO}_{3} / \mathrm{Au}$ device, where ITO-ZnO was biased negatively with different thicknesses of evaporated $\mathrm{Cs}_{2} \mathrm{CO}_{3}$ layer. The inset of a) shows the efficacy (current efficiency) versus the thickness of the $\mathrm{Cs}_{2} \mathrm{CO}_{3}$ layer. 
$\mathrm{Cs}_{2} \mathrm{CO}_{3}$ layer thickness of $4 \mathrm{~nm}$. This current efficiency is very close to that observed for OLEDs using SY as the emitting layer.

The fact that a $\mathrm{Cs}_{2} \mathrm{CO}_{3}$ layer thickness of only $0.25 \mathrm{~nm}$ is sufficient to radically change the HyLED performance, but is insufficient to form a homogeneous layer, indicates that the changes observed are not due to a "layer" effect. It suggests, therefore, that a reaction between the $\mathrm{Cs}_{2} \mathrm{CO}_{3}$ and the SY deposited on top of it takes place at the interface with the $\mathrm{ZnO}$. The modified material that is formed, at this time unidentified, is capable of reducing the barrier for electron injection, while at the same time increasing the barrier for holes.

In summary, using PPV as a light-emitting polymer, we have obtained very efficient and bright electroluminescent devices employing air-stable metal oxides as electrodes. This demonstrates that the HyLED approach is not restricted to the use of light-emitting polymers with low LUMO levels, rendering it more versatile and interesting for applications such as low-cost OLED-based lighting. Bright electroluminescence was obtained from this device only when a thin $\mathrm{Cs}_{2} \mathrm{CO}_{3}$ layer was placed between the $\mathrm{ZnO}$ cathode and the light-emitting layer. Most likely, the $\mathrm{Cs}_{2} \mathrm{CO}_{3}$ layer reacts with the light-emitting polymer forming a thin interfacial electron-injection and hole-blocking layer. These results demonstrate for the first time that HyLEDs are real competitors to conventional OLEDs, and due to their air-stable electrodes with high refractive indices allow for simpler encapsulation and new avenues to increased light outcoupling.

\section{Experimental}

The light-emitting polymer super yellow was kindly donated by Merck. Solvents were obtained from Aldrich. The $\mathrm{ZnO}$ layers were prepared using spray pyrolysis, using a method described previously [27]. Briefly, zinc acetate dihydrate was dissolved in a mixture of ethanol and water (3:1). Acetic acid was added in order to avoid the formation of a white precipitate (zinc hydroxide, $\mathrm{Zn}(\mathrm{OH})_{2}$ ) and to enhance film deposition. This solution was sprayed onto prepatterned ITO glass plates at $400^{\circ} \mathrm{C}$ on a hot plate (prior to deposition, the ITO-coated glass substrates were extensively cleaned, using chemical and UV-ozone methods), and the layers were subsequently annealed in a furnace at $500^{\circ} \mathrm{C}$ for $12 \mathrm{~h} . \mathrm{Cs}_{2} \mathrm{CO}_{3}$ was thermally evaporated under a base pressure of $1 \times 10^{-4} \mathrm{~Pa}$ onto the $\mathrm{ZnO}$-coated substrates. After deposition, the substrates were annealed outside the glove box under ambient conditions at $120^{\circ} \mathrm{C}$ for $10 \mathrm{~min}$. HyLEDs were prepared by spin-coating a thin layer $(50-150 \mathrm{~nm})$ of super yellow from a chlorobenzene solution. Before spin-coating, the solutions were filtered through a $0.20 \mu \mathrm{m}$ poly(tetrafluoroethylene) filter. After spin-coating, the thin films were dried and transferred to a high-vacuum chamber integrated in an inert-atmosphere $\left(<0.1 \mathrm{ppm} \mathrm{O}_{2}\right.$ and $\left.\mathrm{H}_{2} \mathrm{O}\right)$ glovebox. Gold and $\mathrm{MoO}_{3}$ were thermally evaporated under a base pressure of $1.10^{-4} \mathrm{~Pa}$, to serve as anode contact and optical mirror to enhance the unidirectional illumination of the device. The thicknesses of the inorganic layers and spin-coated LEP films were determined using an Ambios XP1 profilometer. Current density and luminance versus voltage were measured using a Keithley 2400 source meter and a photodiode coupled to a Keithley 6485 pico-amperometer using a Minolta LS100 to calibrate the photocurrent. An Avantes luminance spectrometer was used to measure the EL spectrum.

\section{Acknowledgements}

This work has been supported by the European Union (Heteromolmat, STRP 516982, CombOLED, STRP 215934), ESF Eurocores-05SONSFP-021, the Spanish Ministry of Science and Innovation (MICINN) (MAT2006-28185-E, MAT2007-61584, CSD2007-00010), and the Generalitat Valenciana. H. J. B acknowledges the support of the Program "Ramon y Cajal" of the MICINN. Dr. H. Becker and Dr. H. Spreitzer of Merck are acknowledged for the supply of SY.

[1] Y. Sun, N. C. Giebink, H. Kanno, B. Ma, M. E. Thompson, S. R. Forrest, Nature 2006, 440, 908.

[2] K. Walzer, B. Maennig, M. Pfeiffer, K. Leo, Chem. Rev. 2007, 107, 1233.

[3] T. W. Lee, J. Zaumseil, S. H. Kim, J. W. P. Hsu, Adv. Mater. 2004, 16, 2040.

[4] H. J. Bolink, L. Cappelli, E. Coronado, M. Graetzel, E. Ortí, R. D. Costa, M. Viruela, M. K. Nazeeruddin, J. Am. Chem. Soc. 2006, 128, 14786.

[5] J. D. Slinker, J. Rivnay, J. S. Moskowitz, J. B. Parker, S. Bernhard, H. D. Abruña, G. G. Malliaras, J. Mater. Chem. 2007, 17, 2976.

[6] Y. Athanassov, F. P. Rotzinger, P. Péchy, M. Graetzel, J. Phys. Chem. B 1997, 101, 2558.

[7] Z. Zhang, Z. Deng, C. Liang, M. Zhang, D. Xu, Displays 2003, 24, 231.

[8] R. Könenkamp, R. C. Word, M. Godinez, Nanotechnology 2006, 17, 1858.

[9] C. N. R. Rao, B. Raveau, Transition Metal Oxides: Structure, Properties, and Synthesis of Ceramic Oxides, 2nd Ed., Wiley, New York, U.S.A. 1998.

[10] K. Morii, M. Ishida, T. Takashima, T. Shimoda, Q. Wang, M. K. Nazeeruddin, M. Graetzel, Appl. Phys. Lett. 2006, 89, 183510.

[11] H. J. Bolink, E. Coronado, D. Repetto, M. Sessolo, Appl. Phys. Lett. 2007, 91, 223501.

[12] S. A. Haque, S. Koops, N. Tokmoldin, J. R. Durrant, J. Huang, D. C. Bradley, E. Palomares, Adv. Mater. 2007, 19, 683.

[13] H. J. Bolink, E. Coronado, D. Repetto, M. Sessolo, E. Barea, J. Bisquert, G. Garcia-Belmonte, J. Prochazka, L. Kavan, Adv. Funct. Mater. 2008, 18, 145.

[14] D. Kabra, M. H. Song, B. Wenger, R. H. Friend, H. J. Snaith, Adv. Mater. 2008, 20, 3440.

[15] A. J. Campbell, D. D. C. Bradley, H. Antoniadis, Appl. Phys. Lett. 2001, 79, 2133.

[16] S. Quan, F. Teng, Z. Xu, D. Wang, S. Yang, Y. Hou, Y. Wang, Phys. Lett. A 2006, 352, 434.

[17] T. Hasegawa, S. Miura, T. Moriyama, T. Kimura, I. Takaya, Y. Osato, H. Mizutani, SID Int. Symp. Digest. Tech. Papers 2004, 35, 154.

[18] J. Huang, G. Li, E. Wu, Q. Xu, Y. Yang, Adv. Mater. 2006, 18, 114.

[19] C. Wu, C. T. Lin, Y. Chen, M. Chen, Y. Lu, C. C. Wu, Appl. Phys. Lett. 2006, 88, 152104.

[20] J. Huang, T. Watanabe, K. Ueno, Y. Yang, Adv. Mater. 2007, 19, 739.

[21] K. Morii, T. Kawase, S. Inoue, Appl. Phys. Lett. 2008, 92, 213304.

[22] H. Becker, H. Spreitzer, W. Kreuder, E. Kluge, H. Schenk, I. Parker, Y. Cao, Adv. Mater. 2000, 12, 42.

[23] J. L. van Heerden, R. Swanepoel, Thin Solid Films 1997, 299.

[24] P. M. Kumar Ratheesh, C. Sudha Kartha, K. P. Vijayakumar, F. Singh, D. K. Avasthi, Mater. Sci. Eng. B 2005, 117, 307.

[25] Y. Li, D. Zhang, L. Duan, R. Zhang, L. Wang, Y. Qiu, Appl. Phys. Lett. 2007, $90,012119$.

[26] T. Matsumoto, T. Nakada, J. Endo, K. Mori, N. Kawamura, A. Yokoi, J. Kido, SID Int. Symp. Digest. Tech. Papers 2003, 34, 979.

[27] L. van Heerden, R. Swanepoel, Thin Solid Films 1997, 299, 72. 